\title{
Genetic editing of GS3 via CRISPR/Cas9 Accelerates the Breeding of Three- line Hybrid Rice With Superior Yield and Grain Quality
}

\author{
Juan Huang \\ Lijun Gao \\ Shuming Luo \\ Guangxi Academy of Agricultural Science \\ Kaiqiang Liu \\ Guangxi Academy of Agricultural Science \\ Dongjin Qin \\ Guangxi Academy of Agricultural Science \\ Yinghua Pan \\ Guangxi Academy of Agricultural Science \\ Gaoxing Dai \\ Guangxi Academy of Agricultural Science \\ Guofu Deng \\ Guangxi Academy of Agricultural Science \\ Changlan Zhu ( $\sim$ zhuchanglan@163.com) \\ Jiangxi Agricultural University
}

Jiangxi Agricultural University https://orcid.org/0000-0002-5329-8467

Guangxi Crop Genetic Improvement and Biotechnology Laboratory/Guangxi Key Laboratory of Geneti Improvement of Crops, Nanning 530007, China

\section{Research Article}

Keywords: grain size, CRISPR/cas9, yield, grain appearance, three-line hybrid rice

Posted Date: August 26th, 2021

DOI: https://doi.org/10.21203/rs.3.rs-807286/v1

License: @ (1) This work is licensed under a Creative Commons Attribution 4.0 International License. Read Full License 


\section{Abstract}

Grain size is one of the major traits that control rice grain yield and quality. The GS3 gene, a major QTL regulating grain length and weight, is the first one been identified. A mutation occurred in its N-terminal organ size regulating domain (OSR)results in a loss of function of the mutant allele gs 3 and rice varieties carry this gs 3 allele often produce longer grains. In this study, we exploited the CRISPR/Cas 9 gene editing technology to introduce an edited gs 3 allele, two guide RNAs(gRNA) targeted at the OSR of the GS3 gene were transformed into one of our indica maintainer lines, GM1B, for its grain yield and quality improvement. Through molecular analysis and sequencing, in $\mathrm{T}_{1}$ generation, a homologous edited- $g s 3$ mutant line without tansgene was obtained and name as $\mathrm{GM} 2 \mathrm{~B}$, then converted to CMS line GM1A by backcrossing to obtain another superior male sterile line GM2A for further tests. GM2B showed improved grain quality and yield compared to the WT GM1B, with grain length increased by $7.9 \%$, length/width ratio increased from 3.89 to 4.19 , TGW increased by $6.7 \%$, and grain yield per plant increased by $14.9 \%$. Meanwhile, genetic improvement of other quality traits including rice length (6.83mm), rice grain length/width ratio (3.61), matched the appearance standards set for traditional Simiao (silk seedling) type cultivars. Two restorer lines were outcrossed to both GM1A and GM2A to produce hybrid rice. Compared to GM1A's two hybrids, the hybrids of GM2A had longer grains, higher length/width ratio, higher TGW and yield per plant. In addition, hybrids of GM2A showed better performance on grain appearance including better translucency, lower chalky rice rate and chalkiness degree than hybrids of GM1A.These data strongly demonstrate that the introduction of an elite gs 3 allele into GM1A via CRISPR/Cas 9 gene editing technology leads to significant genetic improvement. The resultant CMS line GM2A(gs3) performs much better than the original GM1A on grain quality and yield. Thus, our study proves that targeted genetic improvement using gene editing technology can expedite rice breeding, especially the breeding of three-line hybrid rice.

\section{Introduction}

Rice is an important crop grown in more than 100 countries across the world, and supplies staple food for $2 / 3$ of the world population. The characteristics of grain size (GS) including grain length (GL), grain width (GW), grain thickness(GT) and grain length/width ratio are important factors related to yield and also closely linked to the quality of rice product such as appearance, processing, cooking and taste, etc.. (Xu et al.囚1993;Tan et al, 2000; Xu et al., 2004; Li et al., 2004; Song et al., 2007; Shomura et al., 2008; Wang et al., 2008; Huang et al. 2013; Huang et al. 2017). In the filling process of big and round grain, it is easy to generate chalkiness because of the long transportation route from back to abdomen. Therefore, the transparent and high-quality rice grains are mostly produced in slender grain varieties (Gu et al., 2001; Xu et al., 2004). In recently years, the demand for high-quality slender grain rice has increased significantly in consumer market, which has led to a research hotspot for breeders to cultivate high grain length/width ratio or Simiao-type variety(rice length $\geq 6.5 \mathrm{~mm}$ and rice length/width ratio $\geq 3.5$, T/GDSMM 001-2019) (Fitzgerald et al., 2009; Wang et al., 2012).

Traditional rice breeding methods heavily rely on breeder's experience, and are often inefficient in complex trait selection, which makes the traditional breeding labor and time consuming. The advance of MAS (marker-assisted selection) breeding technology greatly increases breeding efficiency. However, it is somehow limited when low recombination rate exists and genetic drags are hard to break at the target gene/QTL locus. Recently, a genome editing tool derived from an adaptive immune mechanism of microorganisms, the CRISPR-Cas9(clustered regularly interspaced short palindromic repeats/CRISPRassociated protein9)system, has been successfully applied to plants(Shan et al., 2013; Li et al., 2013;Nekrasov et al., 2013). It can precisely modify a plant's own genes without the introduction of foreign genes(Jiang et al.\$2013; Liang et al., 2014;Cai et al., 2015;Lawrenson et al., 2015;lqbal et al., 2016), with which desired traits can be quickly introduced into a target variety , thus, greatly improving breeding efficiency(Tang et al., 2017; soyk et al.,2018; Kuang et al., 2020).

More than 500 QTL genes related to grain size have been identified(http://www.ricedata.cn/ Index. HTM), and 19 QTL genes have been cloned in rice(Chen et

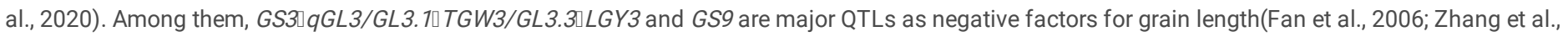
2012; Qi et al., 2012; Ying et al., 2018; Xia et al., 2018; Liu et al. 2018; Zhao et al., 2018). GS3 plays an important role in controlling grain length and grain weight. Loss-of-function at its N-terminal organ size regulating domain (OSR) leads rice plants to produce long type grains. By analyzing the GS3 locus of 78 rice varieties, about half of the indica and one tenth of the japonica contained the long grain allele gs3, indicating the gene's great potential in production(Fan et al., 2006; Mao et al., 2010). Previous studies have showed that the knockout of GS3 gene can obtain longer grain lines which mainly focused on the ovalshaped japonica varieties for germplasm creation, but few on long-shaped indica rice(Han et al., 2018), especially indica hybrid rice(Shen et al., 2016 and 2017; Li et al., 2016; Chen et al., 2020).

The application of three-line hybrid rice(cytoplasmic male sterile line, maintainer line and restorer line) based on nucleo-cytoplasmic interaction has made great contributions to food security in China(Yuan and Tang, 1999). Up to now, the breeding of three-line hybrid rice still faces great challenges including low efficiency to create excellent maintainer lines and high cost of seed production despite breeders' great endeavor. In particular, when the traditional crossselection methods are used to improve maintainer lines and sterile lines, introduction of exogenous elite genes into improved lines often accompanies the introgressive risk of major or minor restoring genes, which greatly decreases efficiency of hybrid rice breeding (Ren et al., 2016). In this study, to test whether introducing a gs 3 allele into an indica CMS (cytoplasmic male sterile) line GM1A could improve the grain quality and yield of its hybrids, we decided to edit the GS3 gene of its maintainer line GM1B with CRISPR/Cas9 technology. GM1A is a derivative of an elite CMS line, MeiA, whose hybrid varieties used to dominate the rice industry with the concept of slender grain size for better quality at the beginning of this century in Guangxi, China (Liang et al., 2001). GM1A inherits many favorable traits including high yield potency, high GCA (general combination ability) from MeiA. as its disadvantage in grain length, it is difficult to use this accession as parent to breed hybrid rice competitively in the current rice market favoring longer, slender(Simao-type) grains and better taste. Thus, we present data to show that introduction of a $g s 3$ allele into GM1A via CRISPR/Cas 9 technology did improve grain quality and yield for both GM1A itself and its hybrids. This genetic improvement system could rapidly establish superior parental lines from small grain to long grain, which laid a foundation for sustainable utilization of existing resources.

\section{Materials And Methods}

\section{Plant materials}


Plant materials included an Indica maintainer line GM1B and its corresponding sterile line GM1A. Restorer lines Guanghui 998(GH998) and Gui 715(G715) were used as the testing parents. These plant materials were grown in the transgenic isolation greenhouse of Guangxi Academy of Agricultural Sciences during the whole experiment.

\section{GS3 genotype detection and its target design in test}

According to the GS3 (Os03g0407400) gene sequence, primer pairs GS3-F1, GS3-R1 and GS3-F2, GS3-R2 were designed near the exons 1 and 2. Sequences of the primers were provided in Table 1. These primers were applied to amplify the DNA templates of the maintainer line GM1B, and the amplified products were sequenced. The sequencing results were then compared with the GS3 (Os03g0407400) gene sequence on the NCBI data base. The exon2 of the GS3 gene in maintainer line GM1Bdid not have the long grain mutation that caused by the C-A bases shift. Using the sequences of the exons 1 and 2 of the GS3 gene in GM1B, gRNA target sites could be designed on a website (http://www.rgenome.net/cas-designer/). To improve the effectiveness of detecting loss-of-function of the target gene, we have selected two targets, target 1 (cctcgaggaatccgatctcgcgg) in the exon 1 and target 2 (tgcagcatctggaggcagcgtgg)in exon 2 . The GC content of targets 1 and 2 was $55.0 \%$ and $70.0 \%$, respectively. The sequences of these two targets were also screened for off-target using the BLAST program on the NCBI website, and there were no off-target sequences matched, indicating an extremely low probability of the off-target.

\section{Vector construction and genetic transformation}

As for the target site sequence, we synthesized ECO31I restriction site with two primer pairs GS3-Y1+, GS3-Y1-, GS3-B1+, and GS3-B1-, respectively (Table 1, the underlined section means the sequence of the restriction site); then mixed equal amount of primer pairs GS3-Y1+/GS3-Y1 and GS3-B1+/GS3-B1-, respectively; constructed the double-stranded DNA fragments at the Eco31I restriction site after denaturation and annealing treatments; ligated the double-stranded DNA fragments to the vectors pBWA and pBWD by restriction endonuclease enzyme and ligase; partially recombined the two constructed vectors containing both the editing elements and the binary vectors to obtain the recombinant plasmid CRISPR-Cas9 -GS3(Fig. 1).

Vector primers YI-R+ and Pbw2- (Table 1) were used for PCR amplification of the 1100 bp editing element in the recombinant plasmid. Amplified products were verified by sequencing and then transferred to the Agrobacterium EHA105. Through the Agrobacterium-mediated transformation method, the whole system (recombinant plasmid CRISPR-Cas9-GS3) was transformed into the callus of the rice variety GM1B. Finally, hygromycin was used to screen the $\mathrm{T}_{0}$ transgenic lines. The whole transformation experiment was entrusted to BioRun company in Wuhan.

\section{Target-site mutations and grain shape variations of the $T_{0}$ transgenic lines}

Positive lines were screened and selected using a hygromycin resistant gene primer pair (Hyg-F/Hyg-R) (Table 1). Initially, primers GS3-F1, GS3-R1, GS3-F2, and GS3-R2 were used to amplify the DNA templates of the positive lines selected, and the PCR products were sequenced. Seedlings of the positive lines and the wild-type materials were thereby planted at the same time, and harvested at maturity stage. Ten full and consistent grains from each single line were selected and measured for grain length using an automatic grain test instrument (Wanshen SC-G, China). Meanwhile, results could be compared with that of the wild type.

\section{Establishment of the long-grain maintainer lines and the sterile lines}

Harvested seeds of the $\mathrm{T}_{0}$ generation were sown into plots, and each plot contained 20 specific lines labeled for testing. Primers Hyg-F/Hyg-R were used to amplify all the DNA template of each individual line in the $\mathrm{T}_{1}$ generation, and WT Nipponbare was used as control. Lines tested with no amplification of the target band were concluded as the transgene-free mutants. Also in the $\mathrm{T}_{1}$ generation, individual GM1B lines characterized with homozygous mutation, significant increase of grain length and no marker gene were selected to outcross to sterile line GM1A. Hybrid seeds or seeds from the mutants of the corresponding maintainer lines were harvested. After multiple backcrossing, the stable sterile line with increased grain length together with its corresponding maintainer line could be selected. Before backcrossing in each generation, the sterile line and the corresponding mutant maintainer were tested for the marker genes to ensure there is no transgene components.

\section{Testing and trait characterization of potential hybrid rice combinations}

After repeated backcrossing and selection, sterile lines with stable long-grain traits were obtained, and each line was tested by sequencing to confirm the edited gs3 loci and free of transgene component. Two restorer lines GH998 (widely used by the hybrid rice industry) and G715(long grain bred by our team) were selected to test the improved long-grain sterile lines together with the original sterile line for hybrid rice combinations. Ten individual plants from each of the 4 hybrid combinations and their female parents, and 5 ones from each of the two restored lines were selected to examine the panicle length and the number of grains for each panicle. Ten full seeds were randomly selected from individual line for trait characterizations including measurements of the grain length, grain width, and the kernel weight of 100 full seeds was measured randomly and then converted into a weight for 1000 grains. Analysis and statistics of the agronomic traits were performed in the GraphPad Prism 8 software, and rice quality analysis for individual lines was in accordance with the standards set in the Quality for Cooking Rice Variety NY/T 593-2013. Fluorescent labeled primers were designed from the penta-primer amplification refractory mutation system (PARMS)(Ye et al., 2001; Zhang et al., 2019; Lu et al., 2020), and these specific lists of primers were used to test the parental genotypes relevant to some rice quality genes such as GS3, Wx, ALK and Chalk5(Fan et al., 2006; Hirano et al., 1998; Isshiki et al., 1998; Gao et al., 2003; Li et al., 2014). Detailed sequences of these primers were provided in Table 1.

\section{Results}

Targeted mutation of GS3 gene generated edited gs3 loci 
Twelve hygromycin resistant primary transformants were obtained and PCR amplification of the hygromycin-resistant gene confirmed that they all carried the selection marker gene. DNA sequencing results of these 12 mutant lines revealed that biallelic mutation occurred in 3 seedlings, two(P437-2, P437-13) were homozygous gs 3 mutants at target 1 and the other(P437-6) was homologus gs 3 mutant at target 2 (Fig. 2). T seeds from each line were harvested individually from $T_{0}$ plants. Grain length and grain width for each line were measured and compared with that of the control(GM1B). Results showed that the average grain length of each three homozygous mutant lines(P437-2, P437-6, P437-13) were longer than 10.00mm whilst the average grain length of WT GM1B was $9.40 \mathrm{~mm}$, indicating a $>5 \%$ increase in grain length (Fig. 2). Sequence alignments of these three homozygous mutants against that of the WT further showed that insertions occurred at both of the two target sites, and disrupted the GS3 open reading frame and resulted premature translation termination. Thus, we generated 3 different edited $g s 3$ loci relevant to the long grain trait.

\section{Selection of transgene-free, homozygous gs3mutants}

Because three primary transformants, P437-2, P437-6 and P437-13, were already homozygotes for $g s 3$ loci, we just needed to identify transgene-free lines from their $\mathrm{T}_{1}$ seedling using PCR amplification of the selection marker, hygromycin-resistant gene (Fig.3). The PCR amplification results allowed us to identify a new line without selection marker from $T_{1}$ offspring of P437-6. After comprehensive survey of target trait (grain length) and other agronomic traits, and sequencing confirmation of the mutation site, line P437-6-2 were selected for further constructing new long-grain sterile line. We named it as Guimei2B (GM2B) for convenience.

\section{Conversion of superior long-grain sterile line GM2A from maintainer GM2B}

The maintainer GM2B carrying the edited $g s 3$ loci was backcrossed to sterile line $\mathrm{GM} 1 \mathrm{~A}$. In the $\mathrm{BC}_{1} \mathrm{~F}_{1}$ segregated population, sterile lines with homozygous mutation and significantly increased grain length were selected to cross with GM2B for propagation and the later generation was named as GM2A (Fig.5). The selection process of male sterile line was presented in Fig.4. To test how the newly-generated mutant CMS GM2A and the WT CMS GM1A perform in agronomic traits, we selected two restorer lines $\mathrm{GH} 998$ and $\mathrm{G} 715$ to form four $\mathrm{F}_{1}$ hybrid rice combinations(Fig.6-7).

\section{Agronomic trait comparison of mutant maintainer GM2B and WT maintainer GM1B}

To investigate whether the knockout of the GS3 gene affects agronomic traits, the major relevant agronomic traits of maintainers GM1B and GM2B were characterized and compared. Traits including the grain length, grain width, ratio of grain length to width, panicle length, grain number per panicle, filled grain number per panicle, seed setting rate, 1000 grain weight, effective tiller number, tiller number at active stage, plant height and weight per plant were scored and data were presented in Fig.5 and Table 3. The statistical analyses of results showed that there was no significant difference between GM1B and GM2B in tillering number, grain width and filled grain number per panicle, but grain length,1000 grain weight and grain number per panicle increased by $7.9 \%, 7.7 \%$ and $25.5 \%$, respectively. Compared to GM1B, although the seed setting rate of GM2B was decreased by $13.6 \%$, its weight per plant was significantly increased by $14.9 \%$. In term of grain yield per plant, the negative effect of decrease in Comparing of relevant traits between their corresponding CMS lines, GM1A and GM2A, resulted in similar conclusions.

\section{Hybrids of GM2A carrying edited gs3 loci performed better in grain length, length/width ratio and yield than hybrids of WT GM1A}

Four hybrid combinations (GM2A/GH998, GM1A/GH998, GM2A/G715and GM1A/G715) were developed by long-grain sterile line GM2A and original sterile line GM1A with two restorer lines GH998 and G715, respectively. Statistical analysis of relevant traits was shown in Table 3, Fig.6, and Fig.7. Compared with GM1A/GH998, the combination of GM2A/GH998 showed 5.6\%, 8.2\%, 7.1\% and $15.4 \%$ increase in grain length, ratio of grain length to width, $1000-$ grain weight and grain weight per plant, respectively, but no significant differences in grain width, panicle length, plant height, grain number, filled grain number, seed-setting rate and effective tillers. In the two combinations of GM2A/G715 and GM1A/G715, there was no significant difference in grain width, grain number, filled grain number, seed setting rate, plant height and effective tiller. However, GM2A/G715 presented a significant increase in grain length, ratio of grain length to width, panicle length, 1000-grain weight and weight per plant than GM1A/G715, by $11.2 \%, 12.6 \%, 3.8 \%$ and $8.1 \%, 15.0 \%$ respectively(Fig.7).

\section{Rice quality analysis}

Due to the grain length and ratio of grain length to width are important factors affecting the appearance quality of rice, the rice length, ratio of rice length to width, translucency grade, chalky rate and chalkiness degree of polished rice grain were performed and the results indicated that the appearance qualities of GM2B(GM2A) and its combinations (GM2A/GH998 and GM2A/GH715) were superior or close to GM1B(GM1A) and its combinations (GM1A/GH998 and $\mathrm{GM} 1 \mathrm{~A} / \mathrm{GH} 715)$ (Fig 8). Especially, the improved parental line GM2B(GM2A, gs3) got the rice length to $6.83 \mathrm{~mm}$, and the ratio of rice length to width to 3.61 comparable to Simiao-type standard. Moreover, the alkali spreading value, gel consistency and amylose content of rice quality were also analyzed (Table 5). Compared with original GM1B(GM1A), the alkali spreading value and gel consistency of improved line GM2B(GM2A) were significantly increased, but there is no difference in amylose content, which is similar to the results of hybrid rice GM1A/GH998 and GM2A/GH998. In the combinations of GH715, GM2A/GH715 exhibited lower amylose content and higher gel consistency, which showed these quality traits of GM2A/GH715 were superior to that of GM1A/GH715. These results indicated that although the head rice rate of processing quality decreased slightly in GM2B(GM2A)and GM2A/GH715(Fig 8), the overall appearance quality and rice qualities of GM2B(GM2A) and its combination (GM2A/GH998 and GM2A/GH715) had been improved, especially in GM2A/GH715. In addition, the genotypes of $G S 3$ and three quality related genes $\left(W x^{b}, A L K\right.$, Chalk5) were also consistent with rice quality testing in Tables 4 and 5.

\section{Discussion}

The characteristics related to rice yield are still important indicators in the new varieties' breeding and previous reports demonstrate that introducing ags 3 gene into a variety substantially increases rice grain yield (Shen et al., 2016; Li et al., 2016; Chen et al., 2020). Comparing the yield related traits of the maintainer 
line GM1B(GS3) and the improved line GM2B $(g s 3)$ demonstrated a significant increase in thousand grain weight (TGW) and grain yield per plant. Even though the seed setting rate of $\mathrm{GM} 2 \mathrm{~B}(\mathrm{gs} 3)$ decreased, increases in grain number per panicle, filled grain per panicle and TGW offset the adverse effect of lower seed setting rate on grain yield. The seed setting rate decrease occurred in our improved maintainer line resembles results of previous studies. Two reports have pointed out that according to the source-sink-flow theory for rice plant growth or cultivation, the increase in grain length, grain weight, and the total number of grains per panicle could have enhanced the 'sink' capacity of the whole grain structure resulting in insufficient photosynthesis in an individual plant, causing more empty grains or a lower seed setting rate (Shen et al., 2016; Chen et al., 2020). However, contrast to the hybrids of original parental line GM1A(GS3), the ones of our improved line GM2A(gs3) had similar seed setting rate and relevant increase of grain length, 1000 grain weight and total yield per plant, thereby ensuring the overall stability of the yield(Table 3). The slender type Simiao or 'silk seedling rice' is very popular in the South China rice market and has high market value. After the introduction of a gs3 allele, the grain length of the resultant male sterile line GM2A meted the grain length standard set of Simiao, which will greatly increase its market competitiveness. Indeed, when GM2A was combined with a slender restorer G715, not only was the yield of their $F_{1}$ product enhanced, but also did the appearance of their $F_{1}$ product matched the high value Simiao standard. In addition, our data also indicated that the edited gs3 allele improved the eating and cooking quality of the male sterile line and its hybrid combinations. Together, our results demonstrated that improvement of GM1A through introducing a gs 3 allele via CRISPR/Cas9 technology indeed lead to better grain appearance and yield in both male sterile line itself and its hybrid combinations.

The values of the rice quality traits for the tested combinations are commonly determined or influenced by the male sterile line used(Mao et al., 2007) and the key to the success of male sterile line breeding is to completely maintain the characteristics of male sterility. Through the CRISPR-Cas9-mediated genome editing technology, some limitations in traditional crop breeding programs can be avoided so as to achieve desired traits quicker and more accurately in the current era of crop genetic improvement(Haque et al. 2018; Mishra et al. 2018). In our rice breeding project, this CRISPR/Cas9-mediated genome editing method was used to knock out the GS3gene in the maintainer line GM1B, and successfully obtained a gs 3 mutant with a specific loss of function of the grain size gene. In the $\mathrm{T}_{1}$ mutant generation of GM1B, specific line with increased grain length and homozygous mutated loci, but without transgene was selected to be the new maintain line $\mathrm{GM} 2 \mathrm{~B}$. In the $\mathrm{BC}_{1} \mathrm{~F}_{1}$ segregated populations, the modified sterile lines were selected base on long grain morphological trait and homozygous mutants and backcrossed with $\mathrm{GM} 2 \mathrm{~B}$ to obtain the corresponding new line $\mathrm{GM}_{2} \mathrm{~A}$ in $\mathrm{BC}_{2} \mathrm{~F}_{1}$ generation. We know that conventional three-line rice breeding system needs a long cycle to evaluate and achieve stable sterile lines, but this report established a breeding system to obtain superior sterile line with target trait and further to develop new cross combinations in only two years, which significantly shortened the breeding cycle for releasing new hybrid rice varieties.

The influence of restoration and conservation relationship on the heterosis of three-line hybrid rice led to more restrictions on trait improvement than conventional rice(Zhou, 1994; Gong et al.,2020). In this experiment, We chose strong restorer line GH998 to further consider the effect of the restored line and improved male sterile line. Otherwise, G715 was selected under the concept of long grain breeding in order to obtain a long grain hybrid combination. The analysis of combinations showed that the maintainer line with single gene knockout kept a good restoration relationship with the restorer line. The improved male sterile lines by gene knockout could be outcrossed to obtain some near isogenic line combinations with single gene mutation for further analyzed (Han et al., 2018), and then some important QTL genes related to rice yield and quality in the tested parents could be detected by PCR-based markers or SNP(single nucleotide polymorphism) primers from high-density arrays in genome-wide association studies (GWAS), to associate the subtle phenotypic effects for different alleles of the gene analyzed. Our results further showed that the test combination with $\mathrm{gs} 3 / \mathrm{gs} 3$ allele had more advantages in yield and quality, indicating that the main QTL gene with negative regulation should pay more attention to the selection of genotype at the corresponding locus of the restorer lines. This experiment is an application attempt of gene editing technology to guide three-line hybrid rice breeding practices from selection of the parents to cross combinations improvement. In the future, these results could not only quicken the effective use of the existing germplasm, shorten the breeding process to release hybrid rice combinations, but also offered new ideas for rice breeders to shift their focus from marker assisted selection (MAS) to genomic selection (Meuwissen et al., 2001), so as to reduce the challenges of phenotyping (Poland and Rutkoski, 2016), and higher the accuracy of genomic prediction using such genetic markers in pre-emptive breeding program (Emebiri et al., 2021).

\section{Abbreviations}

\begin{tabular}{|c|c|c|c|c|}
\hline GM1B & Guimei 1B & GM2B & Guimei 2B & Declarations \\
\hline GM1A & Guimei $1 \mathrm{~A}$ & GM2A & Guimei $2 \mathrm{~A}$ & ents We would like to thank Dr. Chonglie Ma for discussion and \\
\hline CMS & Cytoplasmic male sterility & WT & Wild type & ipt advice to this work. \\
\hline GH998 & Guanghui998 & & Gui715 & \multirow{4}{*}{$\begin{array}{l}\text { Authors' contributions } \mathrm{J} \mathrm{H}, \mathrm{D} Q \text { and } \mathrm{Y} P \text { mainly carried out the sequencing, } \\
\text { agronomic traits statistics and rice quality analysis. } \mathrm{LG} \text { was responsible for } \\
\text { crossing and back-crossing experiments in field. J H, S L, KL and G D performed } \\
\text { data analysis and manuscript writing. G D and C Z contributed to designing the } \\
\text { research. }\end{array}$} \\
\hline TGW & Thousand grain weight & FAM V & FAM value & \\
\hline LC & Low chalkiness & HEX V & HEX value & \\
\hline $\mathrm{HC}$ & High chalkiness & LG & long grain & \\
\hline LASV & Low alkali spreading value & SG & short grain & \multirow{2}{*}{$\begin{array}{l}\text { Funding This work was supported by Guangxi Science and Technology Base and } \\
\text { Special Talents projects (GuiKeAD18050002 and GuiKeAD17129064), Guangxi }\end{array}$} \\
\hline HASV & High alkali spreading value & $\mathrm{AC}$ & amylose content & \\
\hline
\end{tabular}

Zhuang Autonomous Region Natural Science Foundation project(2018GXNSFAA050128) and Science-Technology development foundation of GAAS (GuiNongKe2020YM124).

Availability of data and material The datasets used and/or analyzed during the current study are available from the corresponding author on reasonable request. 
Ethics approval and consent to participate Not Applicable

Consent for publication Not Applicable

Competing interests The authors declare that they have no competing interests.

\section{References}

Cai YP, Li C, Liu XJ, Sun S, Wu CX, Jiang BJ, Han TF, Hou WS (2015) CRISPR/Cas9-mediated genome editing in soybean hairy roots. PloS One 10(8): 1-13

Chen YY, Zhu AK, Xue P, Wen XX, Cao YR, Wang BF, Zhang Y, Shah L, Cheng SH, Cao LY, Zhang YX (2020) Effects of GS3 and GL3.1 for grain size editing by CRISPR/Cas9 in rice. Rice Science 27(5): 405-413

Emebri L, Hildebrand SM, Tan MK, Juliana P, Singh PK, Guentes-Davila G, Singh RP (2021) Pre-emptive breeding against Karnal Bunt infection in common wheat: combining genomic and agronomic information to identify suitable parents. Front Plant Sci 12:675859. Doi:10.3389/fpls.2021.675859

Fan C, Xing Y, Mao H, Lu T, Han B, Xu C, Li X, Zhang QF (2006) GS3, a major QTL for grain length and weight and minor QTL for grain width and thickness in rice a putative transmembrane protein. Theor Appl 112(6):1164-1171.

Fitzgerald MA, Mccouch SR, Hall RD (2009) Not just a grain of rice: The quest for quality. Trends Plant Sci 14(3): 133-139

Gao ZY, Zeng DL, Cui X, Zhou YH, Yan MX, Huang DN, Li JY, Qian Q (2003) Map-based cloning of the ALK gene, which controls the gelatinization temperature of rice. Sci China, Ser C 46(6): 661-668. (in Chinese with English abstract)

Gong R, Huang DQ, Chen YB, Li H, Wang ZD, Zhou DG, Zhao L, Pan YY, Chang YX, Xiang Y, Wang CR, Zhou SC (2020) Comparative metabolomics analysis reveals the variations

of eating quality among three high-quality rice cultivars. Mol Breeding 40:112

Gu YJ, Xiong F, Wang Z, Chen G, Li WF (2001) A Contrast of the Endosperm Development

between Rice and Wheat. J Nanjing Norm Univ, Nat Sci Ed 24(3): 65-74. (in Chinese with English abstract)

Han Y, Luo DJ, Usman B, Nawaz G, Zhao N, Liu F, Li RB (2018) Development of High Yielding Glutinous Cytoplasmic Male Sterile Rice (Oryza sativa L.) Lines through CRISPR/Cas9 Based Mutagenesis of Wx and TGW6 and Proteomic Analysis of Anther. agronomy 8, 290; doi:10.3390

Haque E, Taniguchi H, Hassan MM, Bhowmik P, KarimM R, Smiech M, Zhao KJ, Islam RM (2018) Application of CRISPR/Cas9 genome editing technology for the improvement of crops cultivated in Tropical climates: recent progress, prospects, and challenges. Front Plant Sci doi: 10.3389/fpls.2018.00617

Hirano HY, Eiguchi M, Sano Y (1998) A single base change altered the regulation of the Waxy gene at the posttranscriptional level during the domestication of rice. Mol Biol Evol 15(8): 978-987

Huang HX, Qian Q (2017) Progress in genetic research of rice grain shape and breeding achievements of long-grain shape and good quality japonica rice. Chin J Rice Sci 31(6): 665-672. (in Chinese with English abstract)

Huang RY, Jiang LR, Zheng JS, Wang TS, Wang HC, Huang YM, Hong ZL (2013) Genetic bases of rice grain shape: So many genes, so little known. Trends Plant Sci 18(4): 218-226

Iqbal Z囚Sattar MNखShafia M (2016) CRISPR/Cas9®A tool to circumscribe cotton leaf curl disease. Front Plant Sci 7(231): 475.

Isshiki M, Morino K, Nakajima M, Okagaki RJ, Wessler SR, Izawa T, Shimamoto K (1998) A naturally occurring functional allele of the rice waxy locus has a GT to TT mutation at the $5^{\prime}$ splice site of the first intron. Plant J 15(1): 133-138

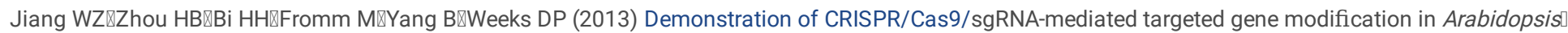
tobacco囚sorghum and rice. Nucleic Acids Res 41(20): e188.

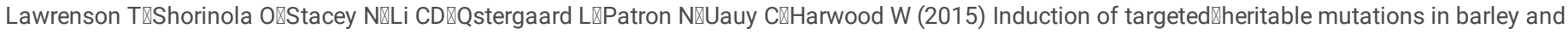
Brassica oleracea using RNA-guided Cas9 nuclease. Genome Biol 16(1): 258-270.

Kuang YJ, Li SF, Ren B, Yan F, Spetz C, Li XJ, Zhou XP, Zhou HB (2020) Base-editing-mediated artificial evolution of OsALS1 In planta to develop novel herbicide-tolerant rice germplasms, Mol Plant 13(4): 565-572.

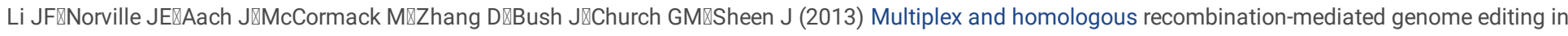
Arabidopsis and Nicotiana benthamiana using guide RNA and Cas9. Nat Biotechnol 31(8): 688-691.

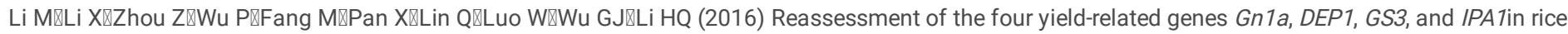
using a CRISPR/Cas9 system. Front Plant Sci 7(12217): 377-389.

Li YB, Fan CC, Xing YZ, Yun P, Luo LJ, Yan B, Peng B, Xie WB, Wang GW, Li XH, Xiao JH, Xu CG, He YQ (2014) Chalk5 encodes a vacuolar H+-translocating pyrophosphatase influencing grain chalkiness in rice. Nat Genet 46(4): 398-404 
Li JM Xiao JH, Grandillo S, Jiang LY, Wan YZ, Deng QY, Yuan LP (2004) QTL detection for rice grain quality traits using aninterspecific backcross population derived from cultivated Asian (O.sativaL.) and African (O. glaberrimaS.) rice. Genome 47: 697-704

Liang Z囚Zhang K囚Chen K囚Gao C (2014) Targeted mutagenesis in Zea mays using TALENs and the CRISPR/Cas system. J Genet Genomics, 41 (2): 63-68.

Liang SR, Zhou M, Deng GF, Chen RT, Wu MS (2001) Breeding of indica CMS line MeiA and its characters analysis. Guangxi Agric Sci 6: 289-291(in Chinese)

Liu Q, Han RX, Wu K, Zhang JQ, Ye YF, Wang SS, Chen JF, Pan YJ, Li Q, Xu XP, Zhou JW, Tao DY, Wu YJ, Fu XD (2018) G-protein ßY subunits determine grain size through interaction with MADS-domain transcription factors in rice. Nat Commun 9: 852

Lu J, Hou J, Ouyang YD, Luo H, Zhao JH, Mao C, Han M, Wang L, Xiao JH, Yang YY (2020) A direct PCR-based SNP marker-assisted selection system(DMAS) for different crops. Mol Breed 40: 1-10

Mao CX, Wan YZ, Ma GH, Shi YM, Zhou H, Song ZP, Wei SF, Xie LP, Wei SB (2006) Current status analysis of hybrid rice development in China. Hybrid Rice 21(6):1-5(in Chinese with English abstract)

Mao HL, Sun SY, Yao JL, Wang CR, Yu SB, Xu CG, Li XH, Zhang QF (2010) Linking differential domain functions of the GS3 protein to natural variation of grain size in rice. Proc Natl Acad Sci 107(45): 19579-19584

Meuwissen THE, Hayes BJ, Goddard ME (2001) Prediction of total genetic value using genome-wide dense marker maps. Genetics 157(4): $1819-1829$. Doi:10.1093/genetics/157.4.1819

Mishra R, Joshi RK, Zhao KJ (2018) Genome Editing in Rice: Recent Advances, Challenges, and Future Implications. Front Plant Sci (9):doi: $10.3389 /$ fpls.2018.01361

Nekrasov V, Staskawicz B, Weigel D, Jones JD, Kamoun S (2013) Targeted mutagenesis in the model plant Nicotiana benthamiana using Cas9 RNA-guided endonuclease. Nat Biotechnol 31(8): 691-693.

Philpot K, Martin M, Butardo V, Willoughby D, Fitzgerald M (2006) Environmental factors that affect the ability of amylose to contribute to retrogradation in gels made from rice flour. J Agric Food Chem 54: 5182-5190

Poland J, Rutkoski J (2016) Advances and challenges in genomic selection for disease resistance. Annu Rev Phytopathol 54: 79-98. Doi:10.1146/annurevphyto-080615-100056

Qi P, Lin YS, Song XJ, Shen JB, Huang W, Shan JX, Zhu MZ, Jiang LW, Gao JP, Lin HX (2012) The novel quantitative trait locus GL3.1 controls rice grain size and yield by regulating Cyclin-T1;3. Cell Research 22:1666-1680.

Ren GJ, Yan LA, Xie HA (2016) Retrospective and perspective on indica three-line hybrid rice

breeding research in China. Chin Sci Bull 61(35): 3748-3760. (in Chinese with English abstract)

Sakamoto T, Matsuoka M (2008) Identifying and exploiting grain yield genes in rice. Curr Opin Plant Biol, 11( 2): 209-214区

Shan QW, Wang YP, Li J, Zhang Y, Chen KL, Liang Z, Zhang K, Liu JX, Xi JJ, Qiu JL, Gao CX (2013) Targeted genome modification of crop plants using a CRISPR-Cas system. Nat Biotechnol 31(8): 686-688.

Shen L, Li J, Fu YP, Wang JJ, Hua YF, Jiao XZ, Yan CJ, Wang KJ (2017) Orientation improvement of grain length and grain number in rice by using CRISPR/Cas9 system. Chin J Rice Sci 31(3): 223-231. (in Chinese with English abstract)

Shen L, Wang C, Fu Y, Wang J, Liu Q, Zhang X, Yan C, Qian Q, Wang KJ (2016) QTL editing confers opposing yield performance in different rice varieties. J Integr Plant Biol 15:1-11.doi囚10.1111/jipb.12501

Shomura A, Izawa T, Konishi S, Ebana K, Kanegae H, Ebitani T, Yano M (2008) Deletion in a gene associated with grain size increased yields during rice domestication. Nat Genet 40, 1023-1028

Song XJ, Huang W, Shi M, Zhu MZ, Lin HX (2007) A QTL for rice grain width and weight encodes a previously unknown RING-type E3 ubiquitin ligase. Nat Genet 39, 623-630

Soyk S, Muller NA, Park SJ, Schmalenbach I, Jiang K, Hayama R, Zhang L, Van Eck J, Jimenez-Gomez JM, Lippman ZB (2016) Variation in the flowering gene SELF PRUNING 5G promotes day-neutrality and early yield in tomato. Nat Genet 49: 162-168.

Tan YF, Xing YZ, Li JX, Yu SB, Xu CG, Zhang QF (2000) Genetic bases of appearance quality of rice grains in Shanyou 63, an elite rice hybrid. Theor Appl Genet 101: 823-829

Tang L, Mao BG, Li YK, Lv QM, Zhang LP, Chen CY, He HJ, Wang WP, Zeng XF, Shao Y, Pan YL, Hu YY, Peng Y, Fu XQ, Li HQ, Xia ST, Zhao BR (2017) Knockout of OsNramp5 using the CRISPR/Cas9 system produces low Cd-accumulating indica rice without compromising yield. Sci Rep 7(1): 14438区

Wang SK, Li S, Liu Q, Wu K, Zhang JQ, Wang SS, Wang Y, Chen XB, Zhang Y, Gao CX, Wang F, Huang HX, Fu XD (2015) The OsSPL 16-GW7 regulatory module determines grain shape and simultaneously improves rice yield and grain quality. Nat Genet 47: 949-954

Page $7 / 15$ 
Wang SK, Wu K, Yuan QB, Liu XY, Liu ZB, Lin XY, Zeng RZ, Zhu HT, Dong GJ, Qian Q, Zhang GQ, Fu XD (2012) Control of grain size, shape and quality by OsSPL 16 in rice. Nat Genet 44(8): 950-954.

Wang ET, Wang JJ, Zhu XD, Hao W, Wang LY, Li Q, Zhang LX, He W, Lu BR, Lin HX, Ma H, Zhang GQ, He ZH (2008) Control of rice grain-filling and yield by a gene with a potential signature of domestication. Nat Genet 40: 1370-1374

Xia D, Zhou H, Liu RJ, Dan WH, Li PB, Wu B, Chen JX, Wang LQ, Gao GJ, Zhang QL, He YQ (2018) GL3.3, a Novel QTL Encoding a GSK3/SHAGGY- like Kinase, Epistatically Interacts with GS3 to Produce Extra-long Grains in Rice. Mol Plant 11: 754-756

Xu R, Yang Y, Qin R, Li H, Qiu C, Li L, Wei P, Yang JB (2016) Rapid improvement of grain weight via highly efficient CRISPR/Cas9-mediated multiplex genome editing in rice. J Genet Genomics 43(8): 529-532

Xu ZJ, Chen WF, Ma DR, Lu YN, Zhou SQ, Liu LX (2004) Correlations between rice grain shapes and main qualitative characteristics. Acta Agron Sin 30(9):894-900. (in Chinese with English abstract)

Xu ZJ, Chen WF, Zhang LB (1993) The difference of quality characteristic and there relation , to yield cultivars. J Shenyang Agric Univ 24(3): 217-223. (in Chinese with English abstract)

Ye S, Dhillon S, Ke X, Collins AR, Day NM (2001) An efficient procedure for genotyping single nucleotide polymorphisms. Nucleic Acids Res 29: e88

Ying JZ, Ma M, Bai C, Huang X, Liu JL, Fan YY, Song XJ (2018) TGW3, a Major QTL that Negatively Modulates Grain Length and Weight in Rice. Mol Plant doi:10.1016/j.molp.2018.03.007.

Yuan LP, Tang CD (1999) Retrospective and current and perspective on hybrid rice breeding. China Rice 1: 3-6. (in Chinese)

Zhang B, Zhao N, Liu YY, Jia L, Fu Y, He XX, Liu KF, Xu ZJ, Bao BL (2019) Novel molecular markers for high-throughput sex characterization of Cynoglossus semilaevis. Aquacult https://doi.org/10.1016/j.aquaculture.2019.734331

Zhang XJ, Wang JF, Huang J, Lan HX, Wang CL, Yin CF, Wu YY, Tang HJ, Qian Q, Li JY, Zhang HS (2012) Rare allele of OsPPKL1 associated with grain length causes extra-large grain and a significant yield increase in rice. PNAS Early Ed doi/10.1073/pnas.1219776110

Zhang Y, Liang Z, Zong Y, Wang YP, Liu JX, Chen KL, Qiu JL Gao CX (2016) Efficient and transgene-free genome editing in wheat through transient expression of CRISPR/Cas9 DNA or RNA. Nat Commun 7:12617| DOI: 10.1038/ncomms12617

Zhao DS, Li QF, Zhang CQ, Zhang C, Yang QQ, Pan LX, Ren XY, Lu J, Gu MH, Liu QQ (2018) GS9 acts as a transcriptional activator to regulate rice grain shape and appearance quality. Nat Commun 9:1240

Zhou K L (1994) Breeding of CMS lines in indica hybrid rice. Hybrid Rice 9: 22-26(in Chinese)

\section{Tables}

Table 1. Primers used in this study 


\begin{tabular}{|c|c|c|}
\hline Primer name & Sequence $\left(5^{\prime}-3^{\prime}\right)$ & Fluorescence value and corresponding genotype \\
\hline GS3-F1 & Tccgccattcaaagcaaagc & - \\
\hline GS3-R1 & Gagtttaggtggagggacgc & - \\
\hline GS3-F2 & Acagtacttgctgtctagcttt & - \\
\hline GS3-R2 & actcccaacgttcagaaattaaatg & - \\
\hline GS3-Y1+ & cagtggtctcaggcaatgggcatgaaccaactcc & - \\
\hline GS3-Y1- & cagtggtctcaaaacggagttggttcatgcccat & - \\
\hline GS3-B1+ & cagtggtctcaggcatcaagactgtccagaaggc & - \\
\hline GS3-B1- & cagtggtctcaaaacgccttctggacagtcttga & - \\
\hline YI-R+ & accggtaaggcgcgccgtagt & - \\
\hline Pbw2- & gcgattaagttgggtaacgccaggg & - \\
\hline Hyg-F & acgtctgtcgagaagtttctgatc & - \\
\hline Hyg-R & agtcaatgaccgctgttatgc & - \\
\hline Chalk5b-FT & gaaggtcggagtcaacggattagagagaagtgccaaggatctgt & HEX V:LC \\
\hline Chalk5b-FC & gaaggtgaccaagttcatgctagagagaagtgccaaggatctgc & FAMV:HC \\
\hline Chalk5b-R1 & tgcatctagctaccttcatttcg & - \\
\hline RGs3-RT & gaaggtcggagtcaacggattcagcaggctggcttactctctt & FAM V: LG \\
\hline RGs3-RG & gaaggtgaccaagttcatgctcagcaggctggcttactctctg & HEX V: SG \\
\hline RGs3-F & acacatgcccatctccctcg & - \\
\hline alk-Ftt & gaaggtgaccaagttcatgcttacaaggagagctggaggggtt & FAM V: LASV \\
\hline alk-Fgc & gaaggtcggagtcaacggatttacaaggagagctggagggggc & HEX V:H ASV \\
\hline alk-R & ctgaggtcctgcgacatgc & - \\
\hline $\mathrm{RWx}-\mathrm{Fg}$ & gaaggtgaccaagttcatgcttcatcaggaagaacatctgcaagg & FAM V: HAC \\
\hline $\mathrm{RWx}-\mathrm{Ft}$ & gaaggtcggagtcaacggatttcatcaggaagaacatctgcaagt & HEX V: L AC \\
\hline RWx-R & ggaaaaacgagcaatgaaagatgc & - \\
\hline
\end{tabular}

Table 2 Single plant of homozygous mutations and their grain length in the $T_{0}$ generation

\begin{tabular}{|c|c|c|c|c|}
\hline $\begin{array}{l}\text { Accession } \\
\text { Numbers }\end{array}$ & Target sequences & $\begin{array}{l}\text { Chromosome } \\
\text { Numbers }\end{array}$ & Sequence of mutation( $\left(5^{\prime}-3^{\prime}\right)$ & Grain length(mm) \\
\hline P437-2 & cctcgaggaatccgatctcgcgg & 2 & CGCGAGATCGGATTCCTTCGAGGGTGAAATAAAT (insertion) & $10.33 \pm 0.36$ \\
\hline P437-6 & tgcagcatctggaggcagcgtgg & 2 & $\begin{array}{l}\text { ATCCACGCTTGCCTCCAGATGCTGCAGAGAGGTTGACGAAT (insertion) } \\
\text { (insertion) }\end{array}$ & $10.22 \pm 0.45$ \\
\hline P437-13 & cctcgaggaatccgatctcgcgg & 2 & CGCGAGATCGGATTCCCTCGAGGGTGAAATAAAT (insertion) & $10.24 \pm 0.41$ \\
\hline GM1B & - & - & - & $9.40 \pm 0.37$ \\
\hline
\end{tabular}

The inserted bases are highlighted in gray.

Table 3 Statistic of variety traits 


\begin{tabular}{|c|c|c|c|c|c|c|c|c|c|c|c|}
\hline variety & $\begin{array}{l}\text { Grain } \\
\text { length } \\
(\mathrm{mm})\end{array}$ & $\begin{array}{l}\text { Gain } \\
\text { width } \\
(\mathrm{mm})\end{array}$ & $\begin{array}{l}\text { Ratio of } \\
\text { grain } \\
\text { length to } \\
\text { width }\end{array}$ & $\begin{array}{l}\text { Panicle } \\
\text { length } \\
(\mathrm{cm})\end{array}$ & $\begin{array}{l}\text { Grain } \\
\text { number per } \\
\text { panicle }\end{array}$ & $\begin{array}{l}\text { Filled grain } \\
\text { number per } \\
\text { panicle }\end{array}$ & $\begin{array}{l}\text { Seed- } \\
\text { setting } \\
\text { rate(\%) }\end{array}$ & $\begin{array}{l}1000 \\
\text { grain } \\
\text { weight(g) }\end{array}$ & $\begin{array}{l}\text { Effective } \\
\text { tiller } \\
\text { number }\end{array}$ & $\begin{array}{l}\text { Tiller } \\
\text { number } \\
\text { at active } \\
\text { stage }\end{array}$ & $\begin{array}{l}\text { Plan } \\
\text { heig } \\
(\mathrm{cm})\end{array}$ \\
\hline GM1B & $9.40 \pm 0.37$ & $2.42 \pm 0.11$ & $3.89 \pm 0.20$ & $25.6 \pm 2.0$ & $163.0 \pm 44.6$ & $141.8 \pm 49.8$ & $84.5 \pm 12.8$ & $18.0 \pm 0.6$ & $10.5 \pm 1.7$ & - & 111. \\
\hline GM2B & $10.14 \pm 0.40$ & $2.42 \pm 0.09$ & $4.19 \pm 0.25$ & $27.7 \pm 2.0$ & $204.5 \pm 34.3$ & $148.4 \pm 26.0$ & $73.0 \pm 8.8$ & $19.2 \pm 0.4$ & $11.0 \pm 1.0$ & - & 112. \\
\hline GH998 & $9.59 \pm 0.36$ & $2.65 \pm 0.13$ & $3.63 \pm 0.25$ & $22.9 \pm 1.5$ & $161.6 \pm 11.7$ & $129.8 \pm 12.2$ & $80.5 \pm 8.6$ & $21.7 \pm 0.5$ & $8.6 \pm 0.9$ & - & 104. \\
\hline G715 & $11.30 \pm 0.37$ & $2.62 \pm 0.14$ & $4.32 \pm 0.33$ & $27.0 \pm 1.3$ & $227.8 \pm 52.7$ & $181.8 \pm 37.7$ & $80.2 \pm 4.3$ & $22.5 \pm 0.7$ & $7.4 \pm 1.1$ & - & 123. \\
\hline GM1A/GH998 & $9.49 \pm 0.30$ & $2.70 \pm 0.08$ & $3.52 \pm 0.14$ & $25.4 \pm 1.0$ & $160.2 \pm 30.2$ & $126.9 \pm 25.9$ & $79.0 \pm 2.9$ & $22.4 \pm 0.7$ & $9.0 \pm 1.5$ & $10.2 \pm 1.1$ & 126. \\
\hline GM2A/GH998 & $10.02 \pm 0.29$ & $2.62 \pm 0.13$ & $3.83 \pm 0.23$ & $25.9 \pm 1.0$ & $167.8 \pm 38.2$ & $126.0 \pm 30.4$ & $75.4 \pm 6.6$ & $24.0 \pm 0.8$ & $10.0 \pm 2.0$ & $12.5 \pm 2.8$ & 128. \\
\hline GM1A/G715 & $9.96 \pm 0.26$ & $2.66 \pm 0.06$ & $3.74 \pm 0.13$ & $26.2 \pm 1.1$ & $193.0 \pm 48.3$ & $149.8 \pm 47.7$ & $76.8 \pm 7.1$ & $22.2 \pm 1.0$ & $8.9 \pm 1.6$ & $10.3 \pm 1.7$ & 131. \\
\hline GM2A/G715 & $11.08 \pm 0.31$ & $2.64 \pm 0.11$ & $4.21 \pm 0.28$ & $27.2 \pm 1.2$ & $214.0 \pm 61.6$ & $163.1 \pm 50.2$ & $76.1 \pm 6.6$ & $24.0 \pm 0.6$ & $11.0 \pm 2.8$ & $12.6 \pm 3.7$ & \\
\hline
\end{tabular}

Table 4 Genotypes of rice quality related genes in tested parents

\begin{tabular}{|c|c|c|c|c|}
\hline Variety & $\begin{array}{l}\text { Fluorescence value and } \\
\text { Genotype of GS3 }\end{array}$ & $\begin{array}{l}\text { Fluorescence value and } \\
\text { Genotype of } W x\end{array}$ & $\begin{array}{l}\text { Fluorescence value and } \\
\text { Genotype of } A L K\end{array}$ & $\begin{array}{l}\text { Fluorescence value and Genotype } \\
\text { of Chalk5 }\end{array}$ \\
\hline GM1B(GM1A) & GS3(FAM V) & $W x^{b}(\mathrm{HEX} V)$ & $A L K(\mathrm{HEX} \mathrm{V})$ & Chalk5(FAM V) \\
\hline $\mathrm{GM} 2 \mathrm{~B}(\mathrm{GM} 2 \mathrm{~A})$ & $g s 3$ & $W x^{b}($ HEX V $)$ & $A L K(\mathrm{HEX} \mathrm{V})$ & Chalk5(FAM V) \\
\hline GH998 & $g s 3(\mathrm{HEX} V)$ & $W x^{b}(\mathrm{HEX} V)$ & $A L K(\mathrm{HEX} \mathrm{V})$ & chalk5(HEX V) \\
\hline G715 & gs3 (HEX V) & $W x^{b}(\mathrm{HEX} V)$ & $A L K(\mathrm{HEX} \mathrm{V})$ & Chalk5(FAM V) \\
\hline GM1A/GH998 & GS3/gs3 & $w x^{b}$ & $A L K$ & Chalk5/ chalk5 \\
\hline GM1A/G715 & GS3/gs3 & $W x^{b}$ & $A L K$ & Chalk5 \\
\hline GM2A/GH998 & gs3 & $W x^{b}$ & $A L K$ & Chalk5/ chalk5 \\
\hline GM2A/G715 & gs3 & $W x^{b}$ & $A L K$ & Chalk5 \\
\hline
\end{tabular}

Table 5 Analysis of rice quality for parents and their cross combinations

\begin{tabular}{|c|c|c|c|c|c|c|c|c|c|c|c|}
\hline Variety & $\begin{array}{l}\text { Brown } \\
\text { rice } \\
\text { rate(\%) }\end{array}$ & $\begin{array}{l}\text { Milled } \\
\text { rice } \\
\text { rate(\%) }\end{array}$ & $\begin{array}{l}\text { Head } \\
\text { rice } \\
\text { rate(\%) }\end{array}$ & $\begin{array}{l}\text { Rice } \\
\text { length } \\
(\mathrm{mm})\end{array}$ & $\begin{array}{l}\text { Rice } \\
\text { width } \\
(\mathrm{mm})\end{array}$ & $\begin{array}{l}\text { Ratio of } \\
\text { rice } \\
\text { length to } \\
\text { width }\end{array}$ & Translucency & $\begin{array}{l}\text { Chalky } \\
\text { rice rate(\%) }\end{array}$ & $\begin{array}{l}\text { Chalkiness } \\
\text { degree(\%) }\end{array}$ & $\begin{array}{l}\text { Alkali } \\
\text { spreading } \\
\text { value }\end{array}$ & $\begin{array}{l}\mathrm{Ge} \\
\mathrm{co} \\
\text { (m }\end{array}$ \\
\hline GM1B(GM1A) & $79.0 \pm 0.2$ & $71.2 \pm 0.7$ & $68.7 \pm 0.7$ & $6.16 \pm 0.15$ & $1.85 \pm 0.08$ & $3.32 \pm 0.16$ & $2 \pm 0$ & $7.0 \pm 2.0$ & $2.4 \pm 0.3$ & $2.3 \pm 0.1$ & 87 \\
\hline $\mathrm{GM} 2 \mathrm{~B}(\mathrm{GM} 2 \mathrm{~A})$ & $78.9 \pm 0.3$ & $70.5 \pm 0.7$ & $66.9 \pm 0.3$ & $6.83 \pm 0.12$ & $1.89 \pm 0.09$ & $3.61 \pm 0.20$ & $1 \pm 0$ & $6.3 \pm 1.5$ & $2.0 \pm 0.6$ & $3.1 \pm 0.2$ & 91 \\
\hline GH998 & $76.9 \pm 0.4$ & $68.2 \pm 0.4$ & $66.5 \pm 0.3$ & $6.93 \pm 0.24$ & $2.27 \pm 0.09$ & $3.05 \pm 0.18$ & $2 \pm 0$ & $9.7 \pm 0.6$ & $5.0 \pm 0.2$ & $2.0 \pm 0.2$ & 88 \\
\hline G715 & $80.0 \pm 1.1$ & $71.8 \pm 1.0$ & $64.0 \pm 0.4$ & $7.38 \pm 0.21$ & $2.19 \pm 0.10$ & $3.37 \pm 0.16$ & $1 \pm 0$ & $8.7 \pm 0.6$ & $2.0 \pm 0.2$ & $2.0 \pm 0.1$ & 66 \\
\hline GM1A/GH998 & $80.3 \pm 0.9$ & $72.4 \pm 0.8$ & $68.8 \pm 0.4$ & $6.63 \pm 0.25$ & $2.26 \pm 0.06$ & $2.94 \pm 0.10$ & $2 \pm 0$ & $10.0 \pm 1.0$ & $3.1 \pm 0.2$ & $2.7 \pm 0.1$ & 78 \\
\hline GM2A/GH998 & $80.2 \pm 0.6$ & $72.4 \pm 0.4$ & $68.3 \pm 0.6$ & $7.10 \pm 0.21$ & $2.21 \pm 0.13$ & $3.21 \pm 0.19$ & $2 \pm 0$ & $8.3 \pm 1.5$ & $3.6 \pm 0.4$ & $3.7 \pm 0.4$ & 84 \\
\hline GM1A/G715 & $77.9 \pm 0.6$ & $70.7 \pm 1.0$ & $68.4 \pm 0.6$ & $6.97 \pm 0.19$ & $2.10 \pm 0.16$ & $3.34 \pm 0.22$ & $1 \pm 0$ & $3.0 \pm 1.0$ & $2.0 \pm 0.3$ & $3.3 \pm 0.3$ & 67 \\
\hline GM2A/G715 & $77.9 \pm 0.3$ & $70.1 \pm 0.4$ & $64.9 \pm 0.7$ & $7.31 \pm 0.17$ & $2.08 \pm 0.06$ & $3.52 \pm 0.11$ & $1 \pm 0$ & $2.0 \pm 0$ & $1.1 \pm 0.1$ & $3.8 \pm 0.5$ & 89 \\
\hline
\end{tabular}

\section{Figures}

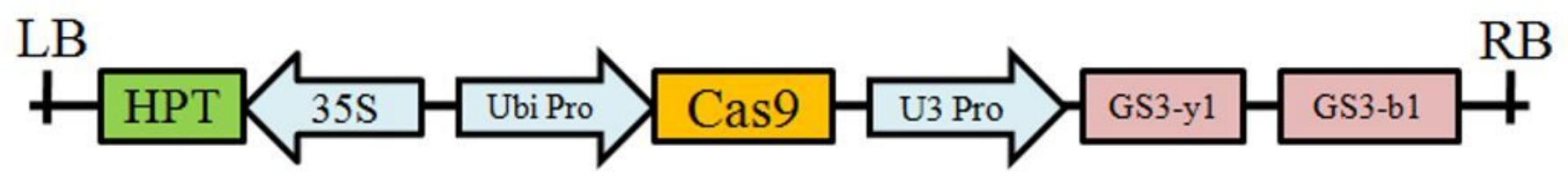

Figure 1 
Schematic map of the recombinant plasmid CRISPR-Cas9 -GS3. The inserted fragment region includes knockout targets GS3-y1 and GS3-b1 activated by U3 promoter, Cas 9 gene activated by ubiquitin promoter and hygromycin phosphotransferase gene activated by $35 \mathrm{~S}$ promoter. LB, T-DNA left border sequence; RB, T-DNA right border sequence.

a

$\begin{array}{cl}\text { GM1B } & \text { CGCGAGATCGGATTCCTCGAGGGTGAAATAAAT } \\ \text { P437-2 } & \text { CGCGAGATCGGATTCCTTCGAGGGTGAAATAAAT } \\ \mathbf{P 4 3 7 - 1 3} & \text { CGCGAGATCGGATTCCCTCGAGGGTGAAATAAAT }\end{array}$

P437-13 CGCGAGATCGGATTCCCTCGAGGGTGAAATAAAT

b

10

20

30

40

50

GM1B MAMAAAPRPKSPPAPPDPCGRHRLQLAVDALHREIGFLEGEINSIEGIHAASRCCREVD

P437-2 MAMAAAPRPKSPPAPPDPCGRHRLQLAVDALHREIGFPRG

P437-13 MAMAAAPRPKSPPAPPDPCGRHRLQLAVDALHREIGFLRG

P437-6 MAMAAAPRPKSPPAPPDPCGRHRLQLAVDALHREIGFLEGEINSIEGIHACLQMLQRG -
GM1B ATCCACGCTGCCTCCAGATGCTGCAGAGAGGTTGACGAAT

P437-6 ATCCACGCTTGCCTCCAGATGCTGCAGAGAGGTTGACGAAT

\section{Figure 2}

sequencing and amino acid analysis of 3 homozygous mutation types of GS3 and their corresponding grain shape. a sequencing analysis of three individuals. Mutations with $1 \mathrm{bp}$ insertion are represented by blue letters and stop codes are in red. b GS3 amino acid alignment of three mutants and wild type. c photograph of grain length comparison between WT and mutants. GM1B, WT maintainer line with GS3 allele; P437-2, -13 and -6, mutant maintainer lines with edited gs3 allele.

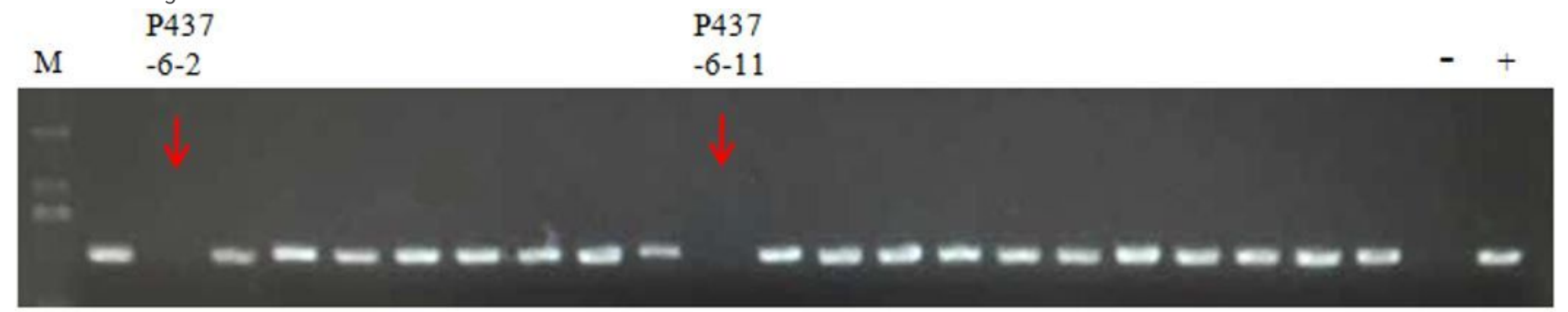

\section{$\begin{array}{llllllllllllllllllllllll}1 & 2 & 3 & 4 & 5 & 6 & 7 & 8 & 9 & 10 & 11 & 12 & 13 & 14 & 15 & 16 & 17 & 18 & 19 & 20 & 21 & 22 & 23 & 24\end{array}$}

Figure 3

PCR identification of the transgene-free transgenic plants. Primers Hyg-R and Hyg-F were used to amplify a fragment from HPT (hygromin phosphotransferase) gene. Lane 1-22, individual seedlings of P437-6 mutant; Lane23, NIP, Negative control(Nipponbare); Lane, 24, +, positive control of transgenic line; M, Marker 2000. Lanes with amplified PCR fragment indicated transgene positive. Lanes without amplified PCR fragment indicated transgenefree. Two transgene-free mutants P437-6-2 and P437-6-11 were pointed with a red arrow. 


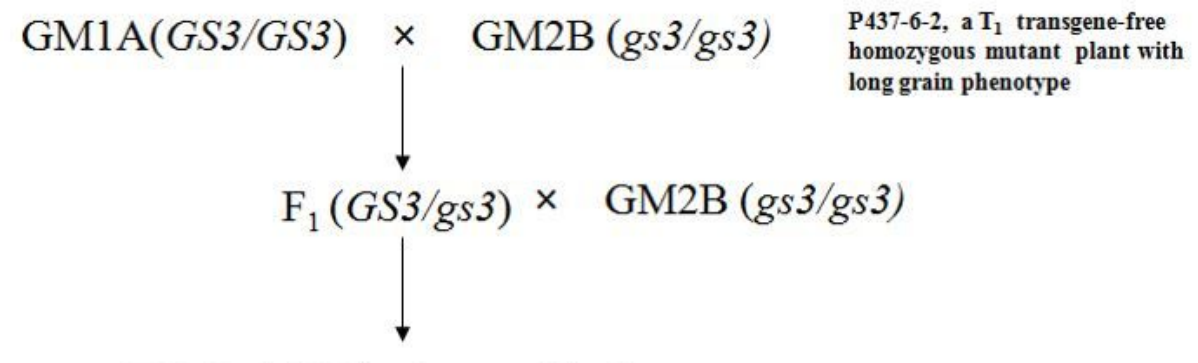

$\mathrm{BC}_{1} \mathrm{~F}_{1}(G S 3 / g s 3$ or gs $3 / g s 3)$

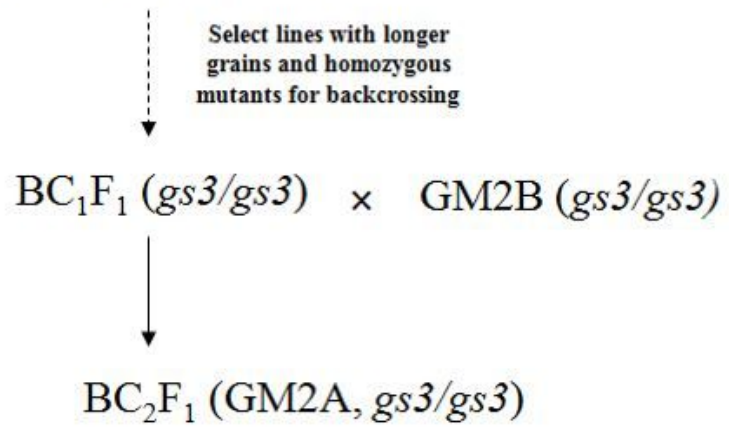

Figure 4

Breeding process of converting mutant maintainer line GM2B to mutant male sterile line GB2A.

a

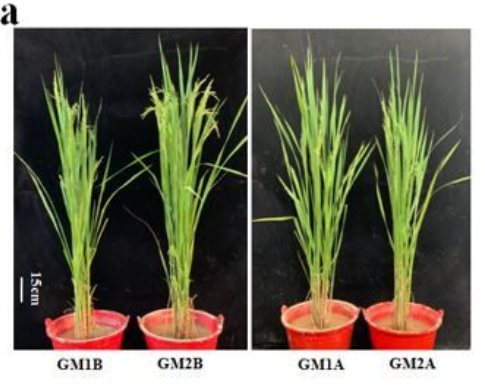

c

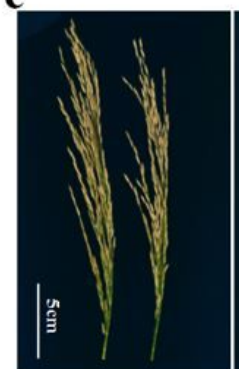

GM2B GM1B b

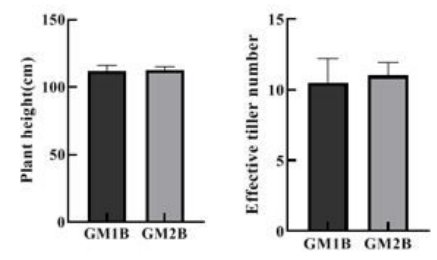

d

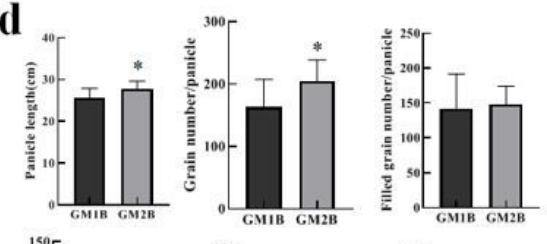

事
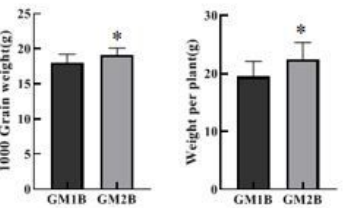
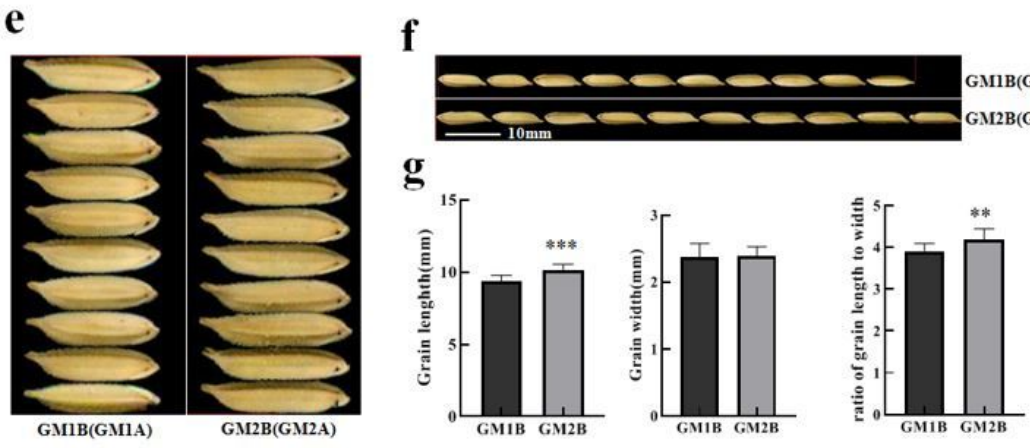

Figure 5 
Comparison of traits of parents and their improved progenies. a, c, e, f shows the grass morphology, panicle and grain of the parent and its improvement. b, $d$, g performances of main agronomic traits of the parent and its improvement. *, **, *** indicate Significant difference at 0.05, 0.01and 0.001 levels.
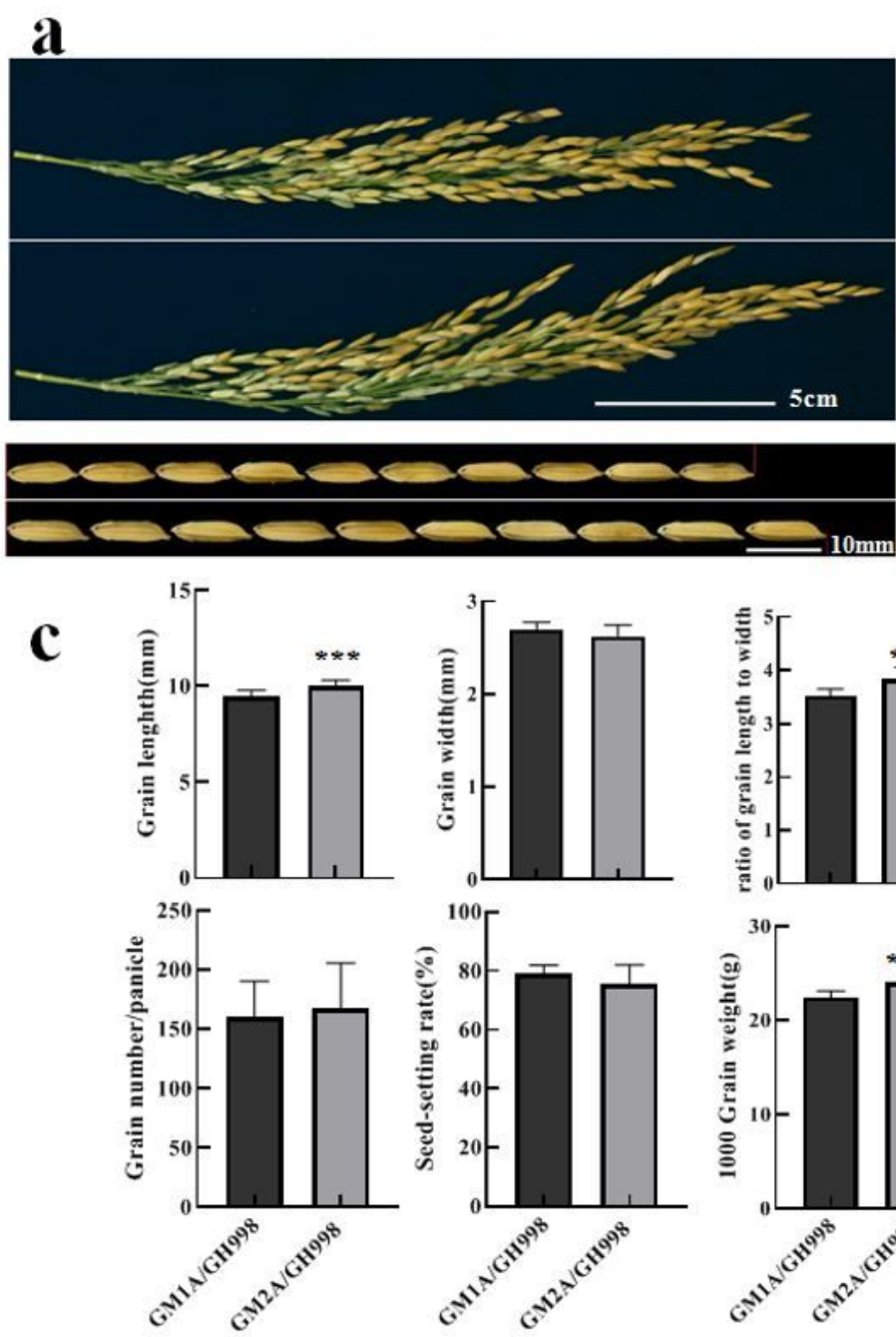
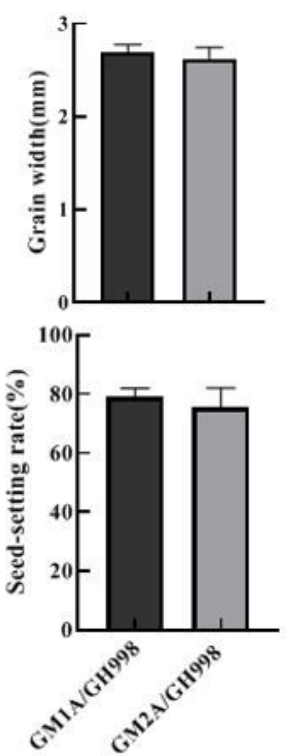

GMlA/GH998

GM2A/GH998

\section{GMlA/GH998}

GM2A/GH998
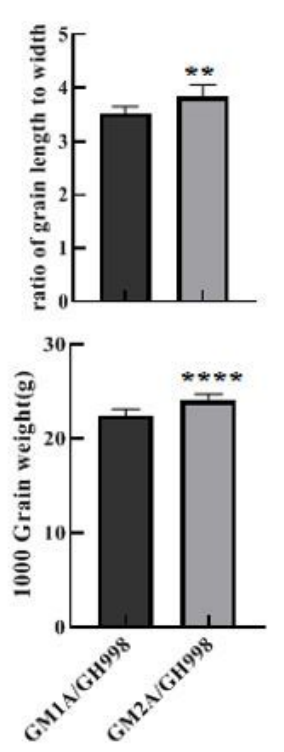
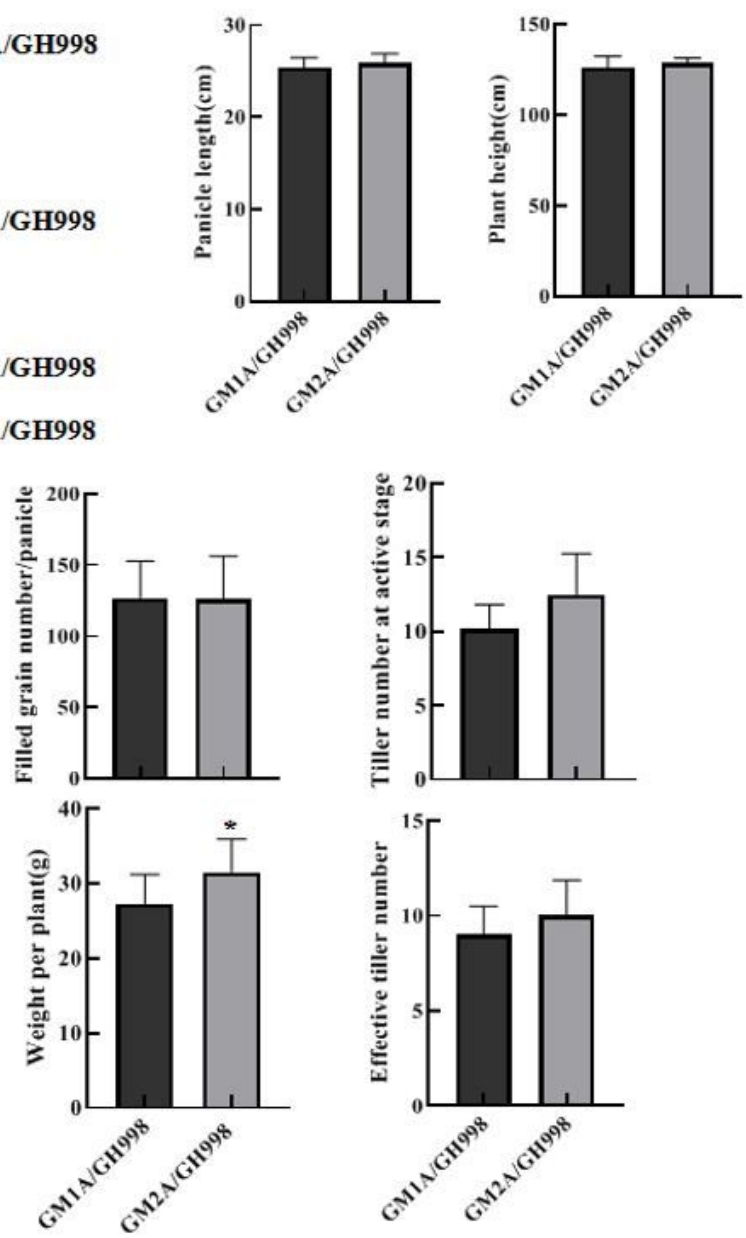

Figure 6

Statistical comparison of traits in GM2A/GH998 andGM1A/GH998. a panicle and grain length of combinations GM1A/GH998 and GM2A/GH998. b, C performances of main agronomic traits of the combination. ${ }^{*}, * \star, * \star \star, * \star \star *$ indicate significant difference at $0.05,0.01,0.001$ and 0.0001 levels. 
$\mathbf{a}$
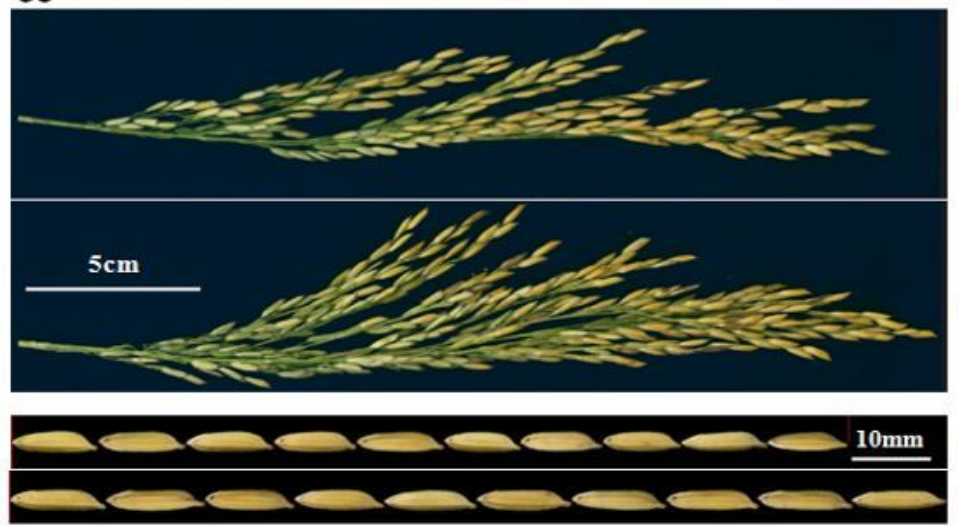

GM1A/G715

GM2A/G715

GM1A/G715

b
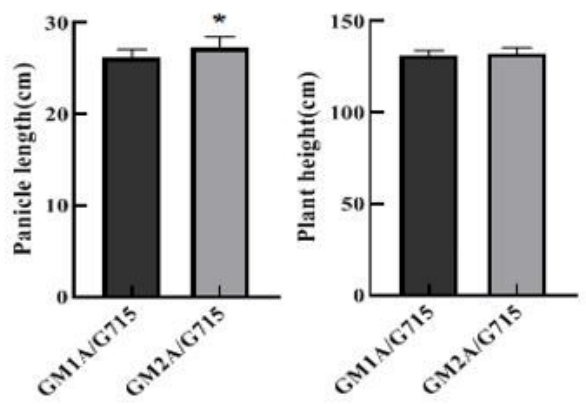

c
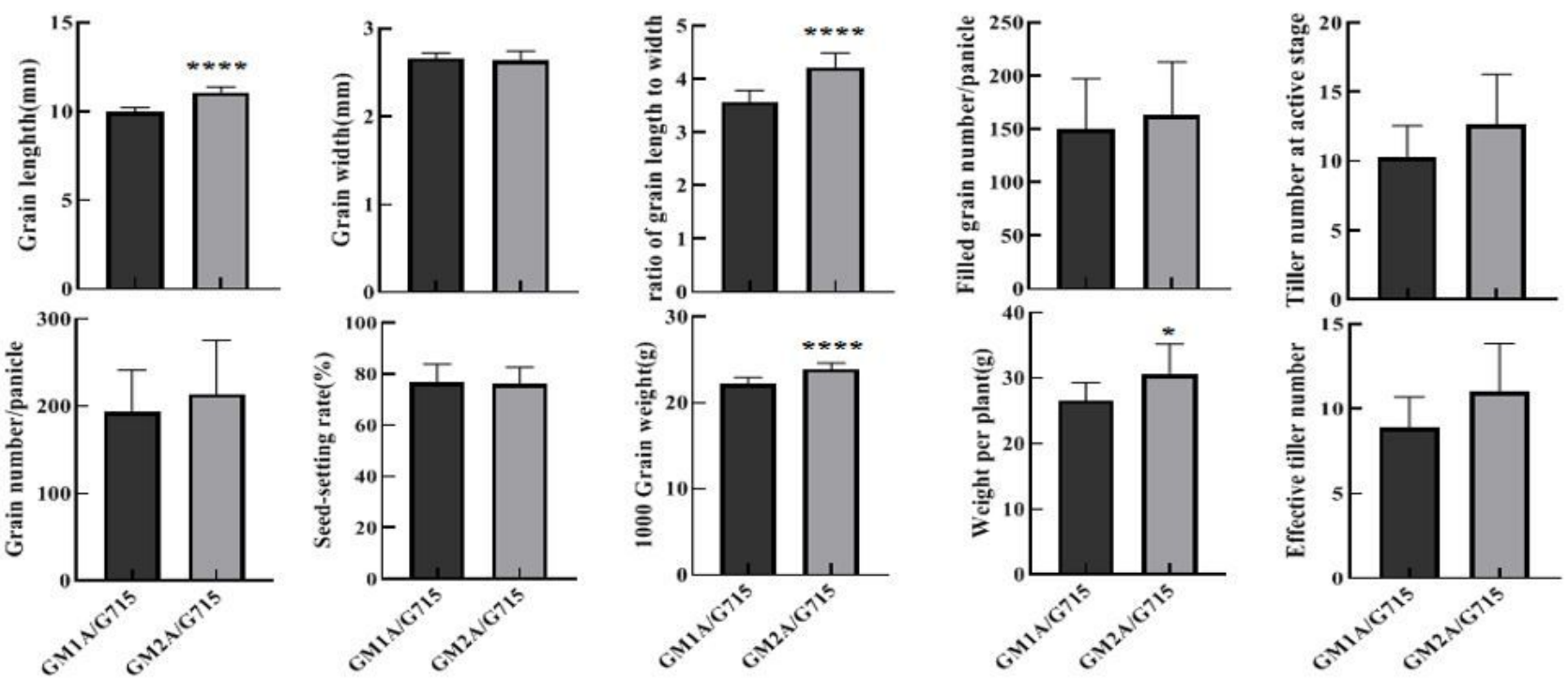

Figure 7

Statistical comparison of traits in GM2A/G715 and GM1A/G715.a panicle and grain length of combinations GM1A/G715 and GM2A/G715. b, c performances of main agronomic traits of the combination. ${ }^{*}{ }^{\star \star \star *}$ indicate significant difference at 0.05 and 0.0001 levels. 
a
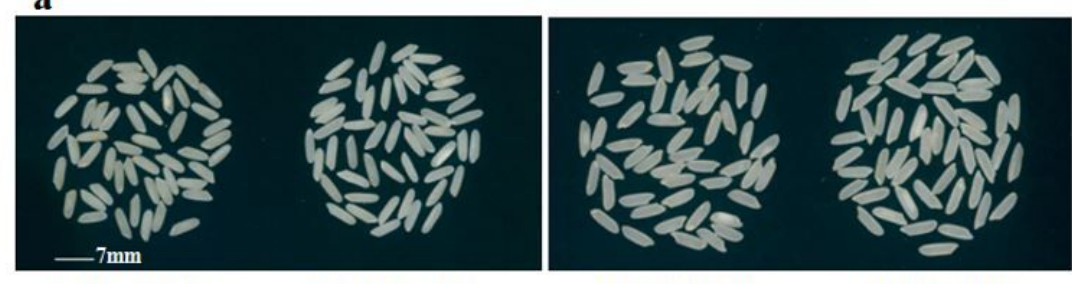

GM1A/GM1B

GM2A/GM2B

GM1A/GH998

GM2A/GH998

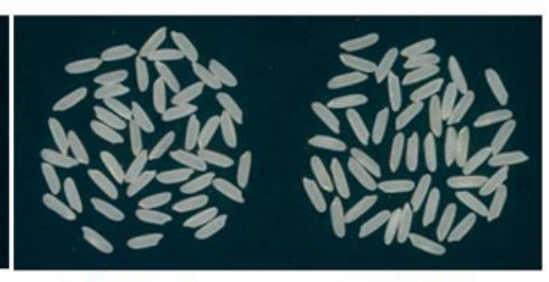

GM1A/G715

GM2A/G715 b
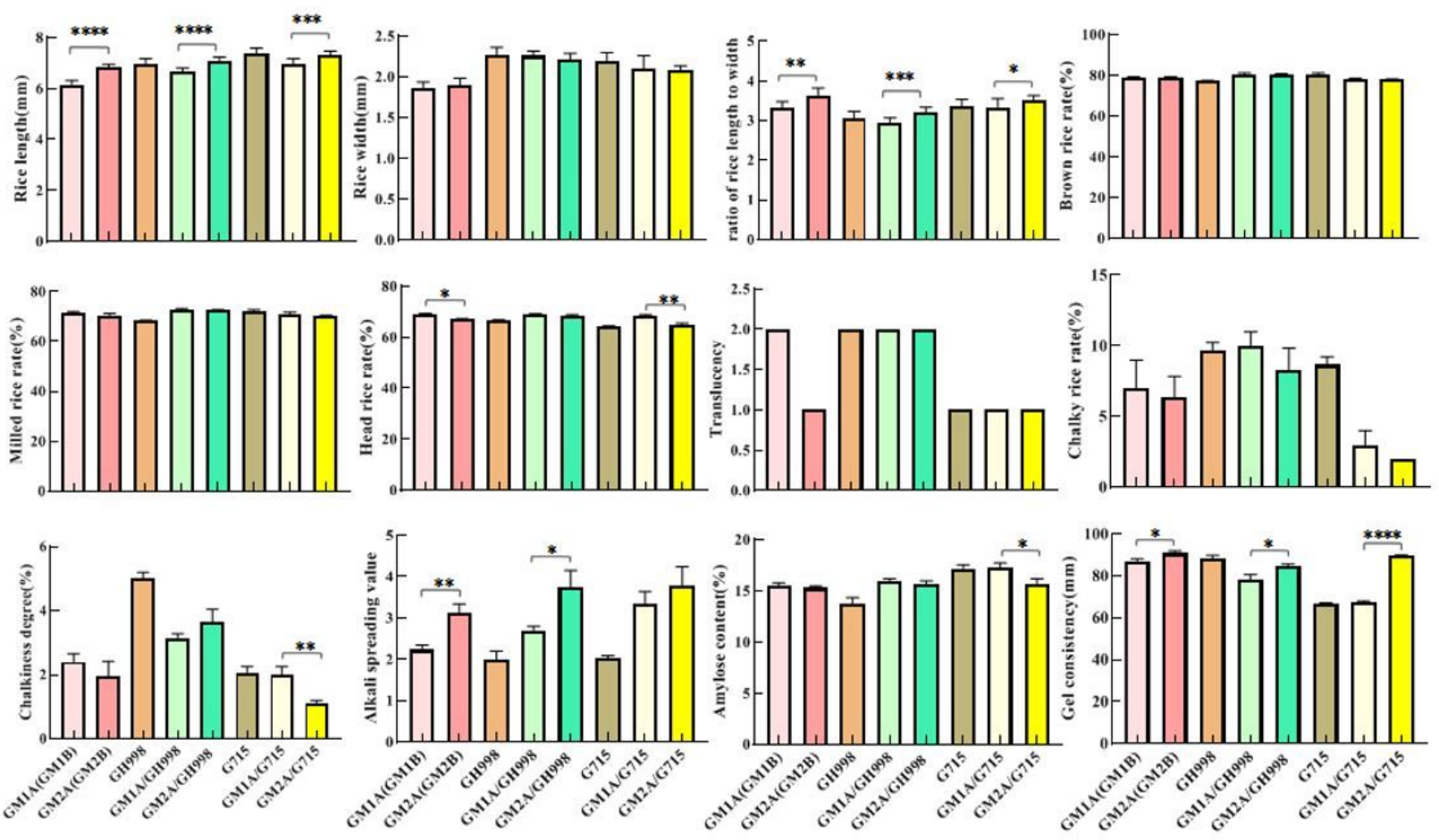

Figure 8

Rice grain quality comparison between parents and their combinations. a Photographs of polished rice grains. $b$ Comparison of grain quality related

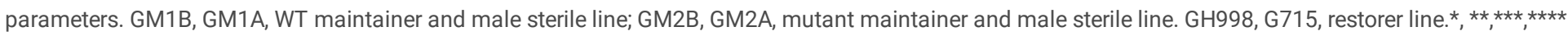
indicate Significant difference at $0.05,0.01,0.001$ and 0.0001 levels. 